Article

\title{
Sex differences in the associations of nutrient patterns with to- tal and regional adiposity: a study of middle-aged black South African men and women
}

Tshifhiwa Ratshikombo ${ }^{1}$, Julia H. Goedecke ${ }^{1,2}$, Melikhaya Soboyisi ${ }^{1}$, Clement Kufe ${ }^{1}$, Maphoko Masemola ${ }^{1}$, Lisa K. Micklesfield ${ }^{1}$, Tinashe Chikowore ${ }^{*}$

1 South African Medical Research Council/WITS Developmental Pathways for Health Research Unit (DPHRU), Department of Paediatrics, School of Clinical Medicine, Faculty of Health Sciences, University of the Witwatersrand, Johannesburg, South Africa

2 Non-Communicable Diseases Research Unit, South African Medical Research Council, Cape Town, South Africa

* Correspondence: tinashedoc@gmail.com.

Abstract: The study evaluated the association between nutrient patterns and body fat and regional adiposity in middle-aged black South African (SA) men and women and determined if this differed by sex. Body fat and regional adiposity (dual-energy x-ray absorptiometry), and dietary intake (7day quantified food frequency questionnaire) were measured in black SA men $(n=414)$ and women $(n=346)$. Using principal component analysis, nutrient patterns were computed from 25 nutrients in the combined sample. Four nutrient patterns were extracted, explaining $67 \%$ of the variance in nutrient intake. Animal and fat, as well as the vitamin C, sugar and potassium driven patterns, were positively associated with total adiposity. In contrast, the retinol and vitamin B12 pattern was associated with the centralisation of fat. Notably, the strength of the association between the animaldriven nutrient pattern and BMI was greater in men $\left(1.14 \mathrm{~kg} / \mathrm{m}^{2}, 95 \% \mathrm{CI}(0.63-1.66)\right)$ than women $\left(0.81 \mathrm{~kg} / \mathrm{m}^{2}, 95 \% \mathrm{CI}(0.25-1.36)\right)\left(\mathrm{P}_{\text {int }}=0.017\right)$. In contrast, the plant driven pattern was associated with higher abdominal subcutaneous adipose tissue (SAT) in women $\left(44 \mathrm{~cm}^{2}, 95 \% \mathrm{CI}(22-67)\right)$ but not men $\left(\mathrm{P}_{\text {int }}=1.54 \times 10^{-4}\right)$. These interactions suggest that although men and women have similar nutrient patterns, the associations with the whole body and regional body fat are different.

Keywords: Nutrient patterns; Obesity; Sex differences; Total and regional adiposity; South Africa

\section{Introduction}

Obesity is a major global health challenge, increasingly affecting developing countries (Finucane et al., 2011). South Africa has the highest prevalence of obesity in Sub-Saharan Africa (Ng et al., 2014; Mchiza et al., 2015; Ajayi et al., 2016), with more women than men (68\% vs $31 \%$ ) presenting with overweight or obesity (SADHS, 2016a). Additionally, middle-aged South African men and women (45-65 years) have the highest obesity rates compared to other age groups (SADHS, 2016b). High body mass index (BMI) is associated with noncommunicable diseases (NCDs), such as cardiovascular disease (CVD), hypertension, atherosclerosis (Barroso et al., 2017), type 2 diabetes, some cancers and premature death (Centers for Disease Control and Prevention, 2013; World Health Organization [Country Office for India], 2014).

Obesity is typically characterised by BMI (Gallagher et al., 1996). However, BMI does not measure body fat distribution, a key risk factor for non-communicable diseases 
(NCDs) (Stenholm et al., 2008; Di Monaco et al., 2011). Central (abdominal) fat, in particular, visceral adipose tissue (VAT), is thought to be the most critical determinant of cardiometabolic risk, whereas peripheral (gluteo-femoral) fat mass is associated with reduced cardiometabolic risk (Preis et al., 2010). Dual-energy X-ray absorptiometry (DXA) provides an objective measure of total and regional adiposity, including estimates of abdominal VAT and subcutaneous adipose tissue (SAT), with greater precision, accuracy and objectivity than anthropometric measures (Plank, 2005; Ellegård et al., 2009; Micklesfield et al., 2012). Notably, women accumulate a higher percentage of body fat, greater peripheral fat mass, less central fat mass and VAT than men (Pisa et al., 2018). However, with increasing age, adiposity and menopause, fat redistribution occurs in women resulting in the accumulation of more VAT (Mtintsilana et al., 2019). It is essential to understand the factors associated with sexual dimorphism of obesity and body fat distribution in middle-aged adults, particularly in Africa, where few objectively measured body fat and its distribution have been conducted (Phillips et al., 2016).

Factors associated with obesity include physical inactivity, sedentary behaviours, socioeconomic status, diet (Yeom, Kim and Crimmins, 2009; Micklesfield et al., 2013; Locke et al., 2015), and urbanisation (Song, Ha and Sung, 2007). With urbanisation, changes in transportation and work activities have reduced physical activity with a consequent reduction in energy expenditure (WHO, 2016a; Guthold et al., 2018). Further, globalisation and urbanisation have increased access to ultra-processed and energy-dense fast foods (WHO, 2016a; Rico-Campà et al., 2019). These foods are high in fat and sugar and are associated with obesity (WHO, 2016b; Rico-Campà et al., 2019). Indeed, a study in South Africa reported that close to half $(48.5 \%)$ of South Africans that consumed fast foods were obese (Otang-Mbeng, Otunola and Afolayan, 2017).

The nutrient pattern analysis for assessing the role of the overall diet emerged as an alternative to traditional approaches that focus on single nutrients $(\mathrm{Hu}, 2002)$. This is advantageous as people consume foods and nutrients in the context of an overall diet. Therefore it is pivotal to evaluate the impact of the whole diet on health outcomes. Due to differences in cultures and foods consumed by people of varying ethnicities, the nutrient pattern analysis approach is now favoured as applicable and comparable across different population groups $(\mathrm{Hu}, 2002)$. Within South Africa, some studies have shown associations between nutrient patterns and obesity in adolescents (Pisa et al., 2015a) and women alone (Makura-Kankwende et al., 2021). However, no studies have evaluated sex differences in nutrient patterns and determined whether the associations between nutrient patterns and total and regional adiposity differ between men and women. Therefore, this study aimed to evaluate the association between nutrient patterns and DXA-derived body fat and regional adiposity in middle-aged black South African (SA) men and women and determine if this differed by sex.

\section{Materials and Methods}

\section{Study population}

This cross-sectional study includes the follow-up data of the longitudinal AWI-Gen (Africa Wits-IN-DEPTH partnerships for Genomic Research) study. Phase 1 data collection was carried out from 2011 and 2015 on black South African men (n=1027) and women ( $n=1008)$ residing in Soweto, South Africa (Ramsay et al., 2016). Follow up data on a sub-sample of 502 men and 527 women randomly selected from the original sample was collected from January 2017 to August 2018. Pregnant and lactating women were excluded from this study. We excluded men and women without DXA data $(n=44)$, weight or height measures $(n=34)$ and physical activity data $(n=240)$ from the final analysis. 
Consequently, 760 (414 men and 346 women) participants had complete data after quality control and were included in the data analysis (see figure 1).

\section{Demographic, Socio-economic and health information}

Demographic characteristics, socioeconomic status and health information of the participants was collected via interviewer-administered questionnaires. This information included age, sex, marital status (categorized as either single, married, divorced, living with a partner or widowed), education (classified as no formal or primary, secondary or tertiary education), employment status (categorized as employed or non-employed), smoking status (categorized as smoker or non-smoker) and HIV status (categorized as HIV positive or HIV negative). Participants not HIV positive completed an HIV antibody test (Wondfo One Step HIV-1/2 Whole Blood/Serum/Plasma: Test 2 lines Guanghu Wondfo Biotech Co., Ltd). If participants tested positive, they were referred to a local HIV clinic but retained in the study.

\section{Body composition and body fat distribution measurements}

Height and weight were measured wearing light clothing and without shoes, from which BMI (weight $(\mathrm{kg}) /$ height $(\mathrm{m})^{2}$ ) was calculated. Weight was measured to the nearest $0.1 \mathrm{~kg}$ using an electronic weight scale (Tanita [TBF-410GS Total Body Composition Analyzer] Tokyo, Japan,) and height was measured to the nearest $0.1 \mathrm{~cm}$ using a wallmounted stadiometer (Holtain, UK). DXA measured the sub-total (total minus head) fat mass and fat-free soft tissue mass (Hologic QDR 4500A, Hologic Inc., Bedford, USA, APEX software version 4.0.2). Regional adiposity was characterised as android and gynoid fat mass and expressed as a percentage of sub-total fat mass (\% fat mass (FM)), as previously described (Woudberg, Lecour and Goedecke, 2019). Abdominal VAT and SAT areas were estimated using DXA, which has been shown to perform a clinical read of VAT from a computed tomography scan (Micklesfield et al., 2012).

\section{Physical activity, sedentary time and energy expenditure}

The activPAL (PAL Technologies, Glasgow, Scotland) accelerometer determined daily steps and sitting time. The participants wore the ActivPAL, fitted on their left thigh to detect limb position using an inclinometer, for at least four consecutive days (of seven days total wear) and a minimum of 10 hours a day. The data was sampled at $10 \mathrm{~Hz}$ in $15-$ seconds epochs. The data was downloaded from the device and processed using ActivPAL 3M software. In addition, metabolic equivalents (METS) per day were extracted from the ActivPAL, which was then converted to kcal by multiplying by body weight (1 $\mathrm{MET}=1 \mathrm{kcal} / \mathrm{kg}$ body weight) to determine the energy expenditure and used to assess the dietary energy intake reporting status described below.

\section{Dietary intake}

Dietary intake was estimated using a seven-day quantitative food frequency questionnaire (QFFQ) consisting of 214 commonly eaten foods derived from analyses of eleven dietary surveys conducted in rural and urban South Africa since 1983 Click or tap here to enter text.(Steyn et al., 2006; Zingoni et al., 2009). To facilitate recall during the QFFQ, flashcards with photographs of the food items were utilised to capture the previous seven-day self-reported dietary intake. Participants separated the food flashcard piles; the first pile included food items rarely/never consumed; the second pile included food items consumed less frequently (occasional); the last (third) pile had food items consumed in the past seven days. The interview then focused on items consumed during the past seven days for the QFFQ. 
Portion sizes were estimated using household measures and a combination of twodimensional life-size drawings of foods and utensils and three-dimensional food models, as described and validated by Steyn and others (Steyn et al., 2006). Coding involved converting the household measures (e.g. one cup/one serving spoon/one slice) to grams. The quantity and frequency of the regular food items consumed were recorded and expressed in $\mathrm{g}$ /day to allow for the average intake to be calculated over the previous seven days. Nutrient composition (energy and macronutrients) was calculated from the conversion of single food items to nutrient compositions, using the nutrient analysis software FoodFinder3, based on South African food composition tables hosted by South African Medical Research Council (SAMRC) (Langenhoven et al., 1991).

Energy intake reporting status was evaluated as the ratio of energy intake: energy expenditure. The energy intake was derived from the QFFQ, and energy expenditure was computed from accelerometry (activPAL). Energy intake: energy expenditure ratio was used to categorise plausible reporters $(0 \cdot 7-1 \cdot 42)$, under-reporters $(<0 \cdot 7)$, and over-reporters (> 1.42) (Jessri, Lou and L'Abbé, 2016). Energy intake reporting status was used in all subsequent analyses.

\section{Statistical analysis}

Data analysis was completed using the statistical package for social scientists (SPSS) version 23 (Statistical Package for the Social Science for Window 23, 2015). Normality tests for the continuous variables were performed using quantile-quantile plots (Q-Q plots) and the Shapiro Wilks test. The descriptive data of the participants were stratified by sex and compared using Chi-square tests for categorical data, t-test for continuous parametric data and the Kruskal Wallis test for non-parametric continuous data.

Principal component analysis (PCA) was used to extract the nutrient patterns based on the QFFQ-derived intake of 25 nutrients. Of these 25 nutrients, total protein was split into animal protein and plant protein; total carbohydrates into total sugar, starch, and total dietary fibre; and total fat categorised as saturated, monounsaturated and polyunsaturated fat. Alcohol was not considered as a nutrient and not included in deriving the nutrient pattern analysis. The nutrient intake variables were log-transformed to remove bias due to variance of the different measures of scale used to quantify the nutrients. Log transformation gives an advantage as it renders the variances and covariance's independent of scale. To control for the variability of nutrient intakes from variation in energy intake, nutrients (log variables) were adjusted for log total energy intake before applying the PCA using the nutrient density approach suggested by Willet (Willett, 1998). PCA was performed with the variance based on the covariance matrix and Varimax rotation. The PCA was a suitable data reduction approach for the nutrient data in this study, as was indicated by a Kaiser-Meyer-Olkin measure of sampling adequacy of 0.911 and a significant $(p<0.001)$ Bartlett's test of sphericity. PCAs were first performed separately for both sexes. However, as the men and women had similar nutrient patterns, the two groups were combined for all subsequent analyses. The retained patterns were determined considering several criteria, including the interpretation of the patterns, the percentage of total variance explained and visual inflexions in the scree-plot (Figure 2) (Hausman et al., 2011). Nutrient patterns were named using the nutrients with absolute loadings greater or equal to 0.47 (Pisa et al., 2015b; Chikowore et al., 2017). Nutrients with positive loadings were significantly associated with a nutrient pattern, while negative loadings were negatively associated. 


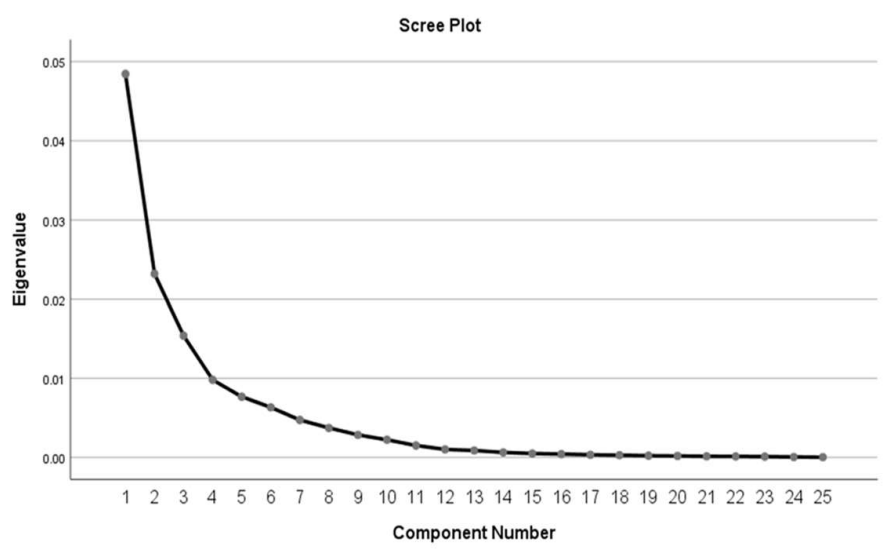

Multivariable linear regression models were computed with BMI, total fat mass (\%), android and gynoid fat mass $(\% \mathrm{FM})$, VAT $\left(\mathrm{cm}^{2}\right)$ and SAT $\left(\mathrm{cm}^{2}\right)$ as outcome variables in the combined sample of men and women. The nutrient patterns were predictors, and the covariates included sex, age, number of steps, sitting time, dietary energy intake reporting status (under, plausible and over-reporters), educational achievement, marital status, smoking, and HIV status. For VAT, body fat $(\mathrm{kg})$ was also used as a covariate. To determine whether the relationships between nutrient patterns with total and regional adiposity differed by sex, we repeated the regression analyses, introduced a nutrient pattern $x$ sex interaction term into the models, and presented any significant interactions as sexstratified analysis. The statistical significance was set at $\mathrm{p}<0.05$.

\section{Results}

\section{Descriptive characteristics of the participants}

The participant's characteristics are presented in Table 1. The mean age in men and women was similar (54 \pm 6 years). $61 \%$ of participants were currently employed. More men than women were married $(\mathrm{P}=0.033)$. Women had a higher mean BMI than men, and a higher proportion of women were classified with obesity (66.5\% vs. $21.5 \%)$. Accordingly, women had a higher sub-total body fat (\%) but had less android (\% FM) and more gynoid (\% FM) fat than men. VAT and SAT areas were higher in women compared to men, but VAT/SAT ratio was higher in men compared to women.

In terms of dietary intake, men consumed more total energy and a higher proportion of protein and fibre than women. In contrast, women consumed a higher proportion of carbohydrates and fat than men. More men were plausible reporters of dietary energy intake than women. As defined by the mean number of steps per day, physical activity was higher in men than women, but men also reported more sedentary time, expressed as mean sitting time per day. A higher percentage of men were smokers $(44.8 \%$ and $6.1 \%$, respectively). HIV status and ARV use did not differ by sex. 
Table 1: Participant characteristics

\begin{tabular}{|c|c|c|c|}
\hline Variables & Men $(n=414)$ & Women $(n=346)$ & $p$-value \\
\hline Age (yrs) & $54 \pm 6$ & $54 \pm 6$ & 0.817 \\
\hline \multicolumn{4}{|l|}{ MEASURE OF SES } \\
\hline \multicolumn{4}{|l|}{ Education (n (\%)) } \\
\hline Primary & $101(24.5)$ & $69(20.1)$ & $<0.001$ \\
\hline Secondary & $231(56.1)$ & $239(68.3)$ & \\
\hline Tertiary & $80(19.4)$ & $40(11.6)$ & \\
\hline \% Employed (n (\%)) & $255(61.7)$ & $212(61.4)$ & 0.934 \\
\hline$\%$ Married (n (\%)) & $208(50.4)$ & 147 (42.6) & 0.033 \\
\hline BMI $\left(\mathrm{kg} / \mathrm{m}^{2}\right)$ & $25.5 \pm 5.9$ & $33.2 \pm 6.5$ & $<0.001$ \\
\hline \multicolumn{4}{|l|}{ BMI categories (n (\%)) } \\
\hline Underweight & $38(9.2)$ & $2(0.6)$ & $<0.001$ \\
\hline Normal weight & $167(40.4)$ & $32(9.2)$ & \\
\hline Overweight & $119(28.8)$ & $82(23.7)$ & \\
\hline Obese & 89 (21.5) & $230(66.5)$ & \\
\hline \multicolumn{4}{|c|}{ TOTAL AND REGIONAL ADIPOSITY } \\
\hline Fat mass $(\mathrm{kg})$ & $18.9 \pm 8.9$ & $35.5 \pm 10.2$ & $<0.001$ \\
\hline Body fat (\%) & $26.0 \pm 6.8$ & $44.6 \pm 5.2$ & $<0.001$ \\
\hline Gynoid (\% FM) & $17.0 \pm 1.9$ & $17.7 \pm 2.7$ & $<0.001$ \\
\hline Android (\% FM) & $8.5 \pm 1.6$ & $7.4 \pm 1.5$ & $<0.001$ \\
\hline $\operatorname{VAT}\left(\mathrm{cm}^{2}\right)$ & $87.4 \pm 46.0$ & $104.1 \pm 44.3$ & $<0.001$ \\
\hline $\operatorname{SAT}\left(\mathrm{cm}^{2}\right)$ & $311 \pm 192$ & $460 \pm 155$ & $<0.001$ \\
\hline VAT/SAT ratio & $1 \pm 0$ & $0 \pm 0$ & $<0.001$ \\
\hline \multicolumn{4}{|l|}{ DIETARY INTAKE } \\
\hline Energy intake (kj) & $8691 \pm 4192$ & $6960 \pm 2923$ & $<0.001$ \\
\hline Carbohydrates (\% EI) & $53.8 \pm 9.3$ & $56.3 \pm 8.4$ & $<0.001$ \\
\hline Protein (\% EI) & $12.1 \pm 3.0$ & $11.5 \pm 2.6$ & 0.009 \\
\hline Fat (\% EI) & $28.9 \pm 7.2$ & $30.9 \pm 7.0$ & $<0.001$ \\
\hline Fibre $(\mathrm{g})$ & $19.9 \pm 9.4$ & $17.6 \pm 8.5$ & 0.001 \\
\hline \multicolumn{4}{|l|}{ LIFESTYLE FACTORS } \\
\hline $\begin{array}{l}\text { Number of steps } \\
(\times 1000)\end{array}$ & $10.6 \pm 4.7$ & $9.2 \pm 3.7$ & $<0.001$ \\
\hline Sitting time (hrs) & $7.8 \pm 1.9$ & $7.1 \pm 1.9$ & $<0.001$ \\
\hline$\%$ Smokers $(\mathrm{n}(\%))$ & $185(44.8)$ & $21(6.1)$ & $<0.001$ \\
\hline \% HIV Positive (n (\%)) & $86(20.9)$ & $66(19.1)$ & 0.527 \\
\hline$\%$ ARVs & $75(92.8)$ & $53(93.0)$ & 0.931 \\
\hline \multicolumn{4}{|c|}{ Dietary energy reporting $(\mathrm{n}(\%))$ : } \\
\hline Underreporting & $176(42.5)$ & $244(70.5)$ & $<0.001$ \\
\hline Over reporting & $34(8.2)$ & $7(2.0)$ & \\
\hline Plausible reporters & $204(49.3)$ & $95(27.5)$ & \\
\hline
\end{tabular}

Values are presented as mean \pm standard deviation or count (percentage). BMI, body mass index; FM, sub-total fat mass; VAT, visceral adipose tissue; SAT, subcutaneous adipose tissue; \%EI, percentage of total energy intake; HIV, human immunodeficiency virus; ARV, antiretroviral therapy

\section{Nutrient patterns}

The nutrient patterns of men and women were not different (data not shown). Table 2 represents the four nutrient patterns retained after PCA, which cumulatively explained $66.9 \%$ of the total variance of the 25 nutrients in the combined sample of men and women. The first PC had high factor loadings for plant protein, starch, B-vitamins, iron and zinc and was termed "Plant Driven Nutrient pattern". This pattern accounted for $30.2 \%$ of the variance in nutrient intake. The second pattern consisted of the high factor loadings of animal protein, cholesterol, fat, fat-soluble vitamins, and vitamin B12. This pattern was named "Animal and Fat Driven Nutrient pattern" and accounted for $17.2 \%$ of the variance in nutrient intake. The third PC accounted for $11.2 \%$ of the variance in nutrient intake, with the greatest factor loading for vitamin $\mathrm{C}$, sugar, potassium, calcium, and dietary 
fibre. This pattern was termed "Vitamin C, sugar, Potassium and Calcium Driven Nutrients pattern". The fourth PC explained $8.1 \%$ of the variance in nutrient intake. This PC contained the highest factor loading for retinol and vitamin B12 and was termed "Retinol and Vitamin B12 Driven Nutrient Pattern".

Table 2: Nutrient patterns and factor loadings for the combined sample of men and women

\begin{tabular}{|c|c|c|c|c|}
\hline Nutrients & $\begin{array}{l}\text { Plant Driven } \\
\text { Nutrien } \\
\text { pattern }\end{array}$ & $\begin{array}{l}\text { Animal } \\
\text { protein and Fat } \\
\text { Driven Nutrient } \\
\text { pattern }\end{array}$ & $\begin{array}{l}\text { Vitamin C, } \\
\text { Sugar and } \\
\text { Potassium } \\
\text { Driven Nutrient } \\
\text { pattern }\end{array}$ & $\begin{array}{l}\text { Retinol and } \\
\text { Vitamin B12 } \\
\text { Driven Nutrient } \\
\text { pattern }\end{array}$ \\
\hline Plant protein & .821 & .116 & .122 & -.056 \\
\hline Animal protein & .131 & .725 & .175 & .243 \\
\hline Saturated fat & .315 & .661 & .206 & .077 \\
\hline Monounsaturated fat & .296 & .712 & .156 & -.017 \\
\hline Polyunsaturated fat & .613 & .565 & .019 & -.064 \\
\hline Cholesterol & .095 & .769 & -.020 & .463 \\
\hline Starch & .799 & .092 & -.167 & -.042 \\
\hline Sugar & .021 & -046 & .726 & .033 \\
\hline Dietary Fibre & .632 & .063 & .477 & -.047 \\
\hline Calcium & .220 & .224 & .555 & .287 \\
\hline Iron & .856 & .295 & .241 & .120 \\
\hline Magnesium & .795 & .135 & .259 & .056 \\
\hline Phosphorus & .739 & .301 & .147 & .142 \\
\hline Potassium & .318 & .079 & .653 & .075 \\
\hline Zinc & .852 & .350 & .173 & .073 \\
\hline Retinol & .080 & .206 & .130 & .960 \\
\hline Beta carotene & .008 & .058 & .279 & -.017 \\
\hline Thiamine & .901 & .287 & .221 & .012 \\
\hline Riboflavin & .754 & .408 & .252 & .307 \\
\hline Vitamin B6 & .674 & .082 & .033 & .014 \\
\hline Folate & .748 & .025 & .067 & .402 \\
\hline Vitamin B12 & .069 & .496 & .073 & .636 \\
\hline Vitamin C & .094 & .181 & .888 & -.019 \\
\hline Vitamin D & .064 & .753 & -.048 & .205 \\
\hline Vitamin E & .256 & .610 & .030 & -.036 \\
\hline Explained variance $\%$ & 30.287 & 17.202 & 11.263 & 8.199 \\
\hline $\begin{array}{c}\text { Cumulative explained } \\
\text { variance } \%\end{array}$ & 30.287 & 47.490 & 58.753 & 66.952 \\
\hline
\end{tabular}

\footnotetext{
Associations between derived nutrient patterns with the selected body composition traits in men and women

Associations between the derived nutrient patterns and the selected body composition traits in men and women are presented in Table 3. The plant driven nutrient pattern was not associated with any of the total or regional adiposity measures. However, there was a significant sex ${ }^{*}$ plant driven nutrient pattern interaction for abdominal SAT (P P $_{i n t}$ $\left.=1.54 \times 10^{-4}\right)$, with the association being significant in women $\left(44.0 \mathrm{~cm}^{2}, 95 \% \mathrm{CI}(21.9 ; 66.5\right.$ $\left.\left.\mathrm{cm}^{2}\right) ; \mathrm{p}=1.21 \times 10^{-4}\right)$ but not men $\left(-3.0 \mathrm{~cm}^{2}, 95 \% \mathrm{CI}\left(-9.52 ; 3.30 \mathrm{~cm}^{2}\right) ; \mathrm{p}=0.341\right)$ as shown in Figure 3.
} 
Table 3: Regression coefficients for 1 SD increase in the derived nutrient pattern scores for selected body composition traits.

\begin{tabular}{|c|c|c|c|c|c|c|c|c|c|c|c|c|}
\hline & BMI & & Body Fat $\%$ & & Gynoid Fat \% & & Android Fat \% & & VAT (cm 2) & & SAT $(\mathrm{cm} 2)$ & \\
\hline & B $(95 \%$ CI $)$ & $p$ & B $(95 \%$ CI $)$ & $p$ & B $(95 \%$ CI $)$ & $p$ & B $(95 \%$ CI $)$ & $p$ & B $(95 \% \mathrm{CI})$ & $\mathrm{p}$ & $\mathrm{B}(95 \% \mathrm{CI})$ & $\mathrm{p}$ \\
\hline $\begin{array}{l}\text { Plant Driven Nutrient } \\
\text { pattern }\end{array}$ & $0.39(-0.02 ; 0.80)$ & 0.065 & $\begin{array}{l}0.05(-0.37 \\
0.46)\end{array}$ & 0.831 & $-0.02(-0.1 ; 0.149)$ & 0.785 & $0.08(-0.03 ; 0.19)$ & 0.153 & $1.12(-1.28 ; 3.53)$ & 0.360 & $-1.10(-5.18 ; 2.99)$ & 0.598 \\
\hline $\begin{array}{l}\text { Animal protein and Fat } \\
\text { Driven Nutrient } \\
\text { pattern }\end{array}$ & $0.80(0.40 ; 1.20)$ & $<0.001$ & $\begin{array}{l}0.91(0.50 \\
1.32)\end{array}$ & $<0.001$ & $0.08(-0.10 ; 0.25)$ & 0.382 & $0.21(0.10 ; 0.32)$ & $<0.001$ & $1.519(-0.90 ; 3.94)$ & 0.218 & $2.37(-1.73 ; 6.47)$ & 0.257 \\
\hline $\begin{array}{l}\text { Vitamin C, sugar and } \\
\text { potassium Driven } \\
\text { Nutrient pattern }\end{array}$ & $0.99(0.59 ; 1.39)$ & $<0.001$ & $\begin{array}{l}0.74(0.32 \\
1.15)\end{array}$ & $<0.001$ & $-0.02(-0.19 ; 0.16)$ & 0.866 & $0.99(-0.01 ; 0.21)$ & 0.081 & $0.79(-1.63 ; 3.21)$ & 0.522 & $0.83(-3.27 ; 4.93)$ & 0.692 \\
\hline $\begin{array}{l}\text { Retinol and Vitamin } \\
\text { B12 Driven Nutrient } \\
\text { pattern } \\
\text { Dietary energy intake re }\end{array}$ & $0.44(-0.34 ; 0.43)$ & 0.819 & $\begin{array}{l}-0.09(-0.48 \\
0.31)\end{array}$ & 0.672 & $\begin{array}{l}-0.16(-0.32 \\
0.003)\end{array}$ & 0.054 & $0.19(0.08 ; 0.30)$ & $<0.001$ & $4.15(1.86 ; 6.44)$ & $<0.001$ & $3.82(-0.07 ; 7.70)$ & 0.054 \\
\hline Underreporting & $5.65(4.75 ; 6.54)$ & $<0.001$ & $\begin{array}{l}4.35(3.44 ; \\
5.27)\end{array}$ & $<0.001$ & $-0.87(-1.25 ;-0.50)$ & $<0.001$ & $0.76(0.51 ; 1.00)$ & $<0.001$ & $-4.97(-10.81 ; 7.46)$ & 0.095 & $1.62(-17.99 ; 21.22)$ & 0.872 \\
\hline Over reporting & $-2.89(-4.67 ;-1.12)$ & $<0.001$ & $\begin{array}{l}-3.46(-5.28 ;- \\
1.65)\end{array}$ & $<0.001$ & $0.07(-0.68 ; 0.82)$ & 0.855 & $-0.36(-0.85 ; 0.13)$ & 0.154 & $-8.93(-20.49 ; 2.64)$ & 0.130 & $3.83(-6.08 ; 13.73)$ & 0.449 \\
\hline \multicolumn{13}{|l|}{$\begin{array}{l}\text { Plausible reporting } \\
\text { (reference) }\end{array}$} \\
\hline Age & $0.02(-0.05 ; 0.08)$ & 0.648 & $\begin{array}{l}0.10(0.03 ; \\
0.17)\end{array}$ & 0.005 & $-0.01(-0.04 ; 0.01)$ & 0.318 & $0.03(0.01 ; 0.04)$ & 0.006 & $0.92(0.52 ; 1.31)$ & $\begin{array}{l}6.85 \mathrm{E}- \\
06\end{array}$ & $0.12(-0.55 ; 0.79)$ & 0.731 \\
\hline $\begin{array}{l}\text { Sex (Male; } \\
\text { female reference) }\end{array}$ & $-5.80(-6.65 ;-4.94)$ & $<0.001$ & $\begin{array}{l}-16.97(- \\
17.85 ;-16.09)\end{array}$ & $<0.001$ & $-1.07(-1.43 ;-0.70)$ & $<0.001$ & $1.35(1.12 ; 1.16)$ & $<0.001$ & $-39.02(-45.47 ;-32.58)$ & $<0.001$ & $-35.19(-46.12 ;-24.26)$ & $<0.001$ \\
\hline $\begin{array}{l}\text { Number of steps } \\
(x \text { 1000) }\end{array}$ & $-0.25(-0.35 ;-0.16)$ & $<0.001$ & $\begin{array}{l}-0.27(-0.37 ;- \\
0.17)\end{array}$ & $<0.001$ & $0.08(0.04 ; 0.12)$ & $<0.001$ & $-0.06(-0.08 ;-0.03)$ & $<0.001$ & $-0.70(-1.30 ;-0.10)$ & 0.021 & $-0.05(-1 .-07 ; 0.96)$ & 0.917 \\
\hline Sitting time (hrs) & $0.28(0.07 ; 0.50)$ & 0.011 & $\begin{array}{l}0.12(-0.11 \\
0.34)\end{array}$ & 0.303 & $0.05(-0.04 ; 0.15)$ & 0.274 & $\begin{array}{l}-0.002(-0.06 ; \\
0.06)\end{array}$ & 0.955 & $-1.13(-2.44 ;-0.19)$ & 0.092 & $-1.89(-4.11 ; 0.34)$ & 0.098 \\
\hline \multicolumn{13}{|l|}{ Education } \\
\hline Primary & $0.88(-0.41 ; 2.18)$ & 0.181 & $\begin{array}{l}0.04(-1.30 \\
1.38)\end{array}$ & 0.952 & $-0.29(-0.85 ; 0.26)$ & 0.301 & $0.002(-0.36 ; 0.36)$ & 0.989 & $1.80(-3.97 ; 7.58)$ & 0.541 & $-7.18(-17.54 ; 9.05)$ & 0.151 \\
\hline Secondary & $-0.02(-1.11 ; 1.06)$ & 0.967 & $\begin{array}{l}-0.07(-1.19 \\
1.06)\end{array}$ & 0.904 & $0.01(-0.45 ; 0.48)$ & 0.962 & $0.06(-0.24 ; 0.37)$ & 0.677 & $-0.38(-8.22 ; 7.46)$ & 0.924 & $-4.25(-16.97 ; 2.72)$ & 0.531 \\
\hline \multicolumn{13}{|l|}{ Tertiary (reference) } \\
\hline Body fat $(\mathrm{kg})$ & & & & & & & & & $3.18(2.89 ; 3.46)$ & $<0.001$ & $13.24(12.76 ; 13.72)$ & $<0.001$ \\
\hline
\end{tabular}

\footnotetext{
$S D$, standard deviation; $C I$, confidence interval; EI, energy intake; $E E$, energy expenditure
} 


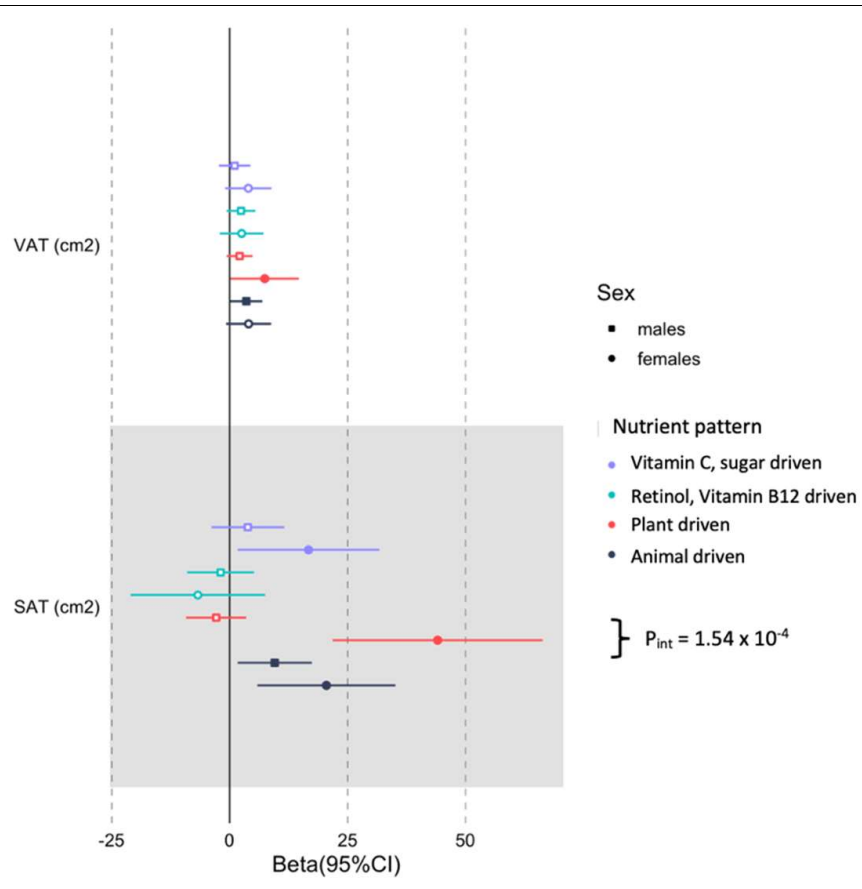

Figure 3. Stratified abdominal subcutaneous adipose tissue (SAT) and visceral adipose tissue (VAT) associations with nutrient patterns in middle-aged black SA men and women. The associations are adjusted for age, number of steps, education status, SES status, energy intake reporting and fat mass index. Non-significant effect sizes are indicated as hollow.

In the combined sample, we found that the animal and fat driven nutrient pattern was positively and significantly associated with BMI, body fat \% and android \% FM (Table 3). For BMI only there was a significant sex*animal-driven nutrient pattern interaction ( $P_{i n t}$ $=0.017)$, such that the strength of the association was greater in men $\left(1.1 \mathrm{~kg} / \mathrm{m}^{2}, 95 \% \mathrm{CI}(0.6-\right.$ $\left.\left.1.7 \mathrm{~kg} / \mathrm{m}^{2}\right), \mathrm{p}=1.75 \times 10^{-5}\right)$ compared to women $\left(0.8 \mathrm{~kg} / \mathrm{m}^{2}, 95 \% \mathrm{CI}\left(0.3-1.4 \mathrm{~kg} / \mathrm{m}^{2}\right) ; \mathrm{p}=\right.$ 0.004) (Figure 4). 


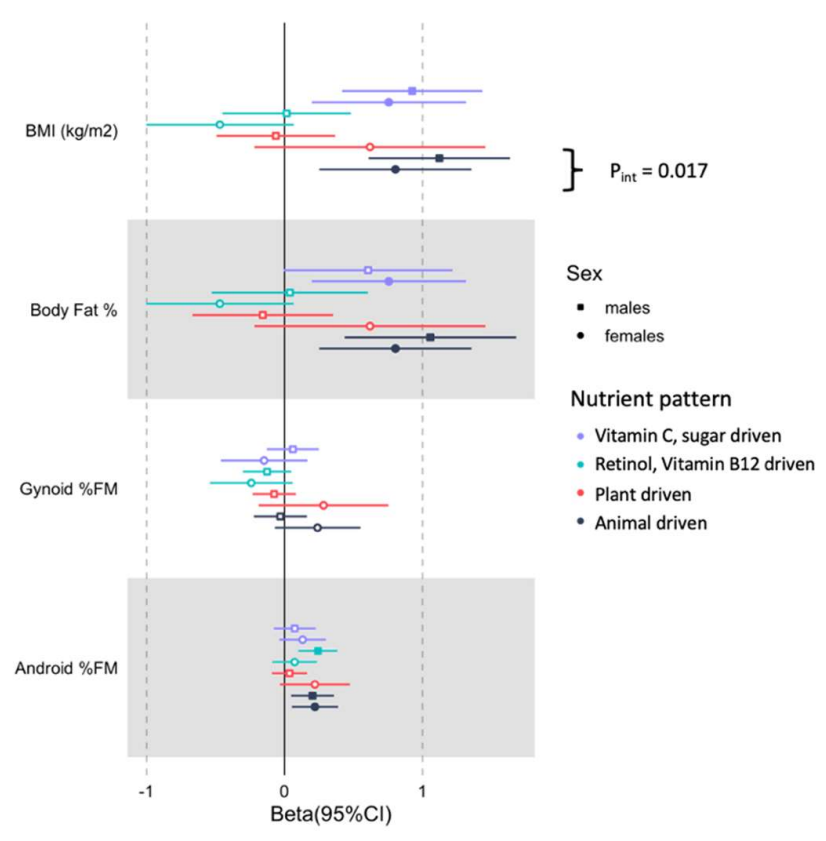

Figure 4. Stratified associations of total and regional adiposity with nutrient patterns in middle-aged black SA men and women. The associations are adjusted for age, number of steps, education status, SES status and energy intake reporting. A significant interaction between sex and animal-driven nutrient pattern on BMI was noted $\left(P_{\text {int }}=0.017\right)$. Non-significant effect sizes are indicated as hollow.

The Vitamin C, sugar and potassium driven nutrient pattern was positively associated with BMI and body fat $\%$ in the combined sample (Table 3). The retinol and vitamin B12 pattern was not associated with total adiposity (BMI or body fat) but was associated with body fat distribution, being positively associated with android FM and VAT, with a tendency to be negatively associated with gynoid fat mass $(\mathrm{P}=0.054)$.

\section{Discussion}

Our study identified four nutrient patterns that explained $67 \%$ of the variation in nutrient intake in middle-aged black South African men and women. The plant-driven nutrient pattern explained most of the variance (30\%). Although not associated with any of the body fat measures for the combined sample, it was associated with higher abdominal SAT in the women but not the men. The animal and fat driven pattern was associated with greater total and android adiposity. It showed sexual dimorphism in its association with BMI, with the strength of the association being greater in men than women. The vitamin C, sugar and potassium driven nutrient pattern was associated with greater total adiposity as measured by BMI and whole body \% fat. In contrast, the retinol and vitamin B12 driven pattern was associated with the centralisation of body fat in the combined sample, with the association with android fat mass being driven by the association in men.

Four studies to date have characterised nutrient patterns of black South Africans. Two of these studies focused on children and adolescents (Pisa et al., 2015b; Visser et al., 2019), while the others focused on adults (Chikowore et al., 2017; Makura-Kankwende et al., 2021). Similar to our findings, the plant-driven nutrient pattern is the most commonly consumed in South Africa. It is characterised by high factor loadings of magnesium, 
phosphorus, plant protein, carbohydrates, iron, B-vitamins and fibre (Visser et al., 2019). The food sources for this nutrient pattern includes staple foods such as refined maize meal, which is widely consumed and fortified with B vitamins in South Africa (FAO, 2018). Although the plant driven nutrient pattern was not significantly associated with total or regional fatness in the combined sample of men and women, we show for the first time that this nutrient pattern was associated with higher abdominal SAT in women but not men. The intake of refined carbohydrates has been associated with increases in abdominal SAT in both men and women (McKeown et al., 2010), but the reasons for the sexual dimorphism in this relationship is not clear. We may postulate that hyperinsulinemia observed in black African women compared to men may drive this relationship (Goedecke et al., 2009; Goedecke and Olsson, 2020). Together with the high consumption of processed carbohydrate-rich foods, hyperinsulinemia will drive lipogenesis and SAT accumulation (Gower and Fowler, 2020. This may explain this sex-specific relationship and provide a plausible reason why black African women accumulate more abdominal SAT than their male and white European counterparts (Goedecke et al., 2009; Keswell, Tootla and Goedecke, 2016). However, prospective intervention studies are required to verify these suggestions.

The animal protein and fat-driven nutrient pattern, characterised by animal protein, saturated fat, monounsaturated fat, polyunsaturated fat, and cholesterol, was associated with total and central adiposity. This was the second most consumed nutrient pattern and suggested a shift towards a Westernised diet characterised by increased consumption of energy-dense foods, meat, butter, eggs and oils (FAO, 2018), which have been associated with obesity. Notably, we also showed sexual dimorphism in the relationship between animal protein and fat driven nutrient pattern and BMI, showing a stronger relationship in men than women. Socio-cultural perspectives may likely cause this relationship. Traditionally, black SA households are strongly patriarchal, with the nutritional needs of men being prioritised over that of women, particularly relating to protein-rich foods, especially meat (Puoane et al., 2006). Conversely, one study reported that the young black SA women are also health-conscious and try to minimise foods high in fat (FAO, 2018).

The "vitamin C, sugar and potassium" driven nutrient pattern, which explained $11.7 \%$ of the variance in nutrient intake in our sample, suggest a diet high in the consumption of sugar sugar-sweetened beverages such as carbonated soft drinks fruit juices and tea with milk. The association of added sugars with increased BMI was reported in black South Africans in a longitudinal five-year study and a representative cross-sectional in South African rural and urban areas (Vorster et al., 2014; Steyn et al., 2016). Similarly, we showed that this nutrient pattern was associated with higher total body fatness in the combined sample and higher abdominal SAT in women. These sex differences might have been due to tea beverages that are more commonly consumed by women than men in this population (FAO, 2018). Liquid foods such as sugar-sweetened beverages (SSBs) are less satiating. They have a lower thermic effect than solid foods of similar nutrient composition and energy, leading to higher energy intake, positive energy balance and excess fat accumulation (Malik et al., 2010).

The retinol and vitamin B12 driven nutrient pattern, suggestive of fish- and animalbased food sources were associated with greater centralisation of body fat (android \% FM and VAT) only. Contrary to our results, previous studies reported that vitamin B12 was negatively associated with obesity in Copenhagen adults aged 18 to 60 years (Yagan et al., 2016; Allin et al., 2017). However, this was a single nutrient association with obesity, and the association for the combination of retinol and vitamin B12 has not been explored. More 
research is required to understand this association, which, when stratified by sex, was weakened and only showed a significant association with android \% FM in men only.

Our study was limited in that it was a cross-sectional design from which we cannot infer causality. Thus, our study findings will need to be confirmed in prospective randomised clinical trials. Although using self-reported dietary data is a practical tool in all nutritional epidemiological studies, there are limitations around measurement error and final estimation of the nutrient intake. However, the current study used a validated QFFQ, with a list comprising 214 foods eaten by the South African population, which is known to be comprehensive, and was also corrected for energy intake reporting (Steyn et al., 2006). The strengths of our study included the use of nutrient patterns as opposed to dietary patterns since nutrients are universal and comparable among different ethnicities (Pisa et al., 2015b; Chikowore et al., 2017). We used DXA to characterise body fat and regional adiposity objectively. The models were adjusted for energy intake reporting bias that comprised energy intake expenditure derived from objective measures of physical activity (accelerometry). In addition, we adjusted for physical activity and sedentary behavior (measured objectively using accelerometry), which are known to influence dietary intake and adiposity.

\section{Conclusions}

In conclusion, we showed that nutrient patterns that characterize high intakes of animal protein and fat, as well as vitamin C, sugar, and potassium, were associated with total adiposity, while the animal protein and fat, as well as the B12 driven nutrient patterns, were associated with central adiposity in middle-aged black SA men and women. The study's novel findings were the sexual dimorphism in the association between the plant-driven nutrient pattern and abdominal SAT and animal and fat driven nutrient pattern with BMI. These findings suggest that Westernization of diets, with increased animal fat and sugar consumption, are associated with higher adiposity and risk for noncommunicable diseases in middle-aged black South Africans. Sexual dimorphism in these associations suggests that men may be more susceptible to obesity when consuming a diet rich in animal protein and fat. In contrast, women may be more susceptible to abdominal SAT accumulation when consuming a staple diet high in processed carbohydrates. Future studies are required to explore the mechanisms underlying these associations, which may provide greater insights into the pathogenesis of obesity and inform sex-specific dietary approaches to curb this increasing burden of disease.

Author Contributions: study conception and design: JHG and LKM; data collection: TR, CK, MM, TC; data analysis: TR, TC; interpretation of results: TR, JHG, TC; draft manuscript preparation: TR, TC, JHG. All authors have read and agreed to the published version of the manuscript.

Funding: The study was jointly funded by the South African Medical Research Council (MRC) from South African National Department of Health, MRC UK (via the Newton Fund) and GSK Africa Non-Communicable Disease Open Lab (via a supporting Grant project Number: ES/N013891/1) and South African National Research Foundation (Grant no: UID:99108). TC is an International Training Fellow supported by the Wellcome Trust grant (214205/Z/18/Z). TR was funded by a National Research Foundation Freestanding, Innovation and Scarce Skills Development Masters and Doctoral Scholarships (Grant No: SFH160708176628).

Institutional Review Board Statement: The study was conducted according to the guidelines of the Declaration of Helsinki and approved by the University of the Witwatersrand Human Research Committee (Reference: M160604, M160975 and M180610). 
Informed Consent Statement: Written informed consent was obtained from all subjects involved in the study after full explanation of the study's objectives and testing procedures.

Acknowledgments: We are grateful to the participants as well as the following DPHRU staff for their input during data collection and entry: Vukosi Mkansi, Sphume Thango, Mosadiapula Nakedi, Bonisiwe Mlambo and team

Conflicts of Interest: The authors declare no conflict of interest.

\section{References}

1. Ajayi, I.O.O. et al. (2016) "Urban-rural and geographic differences in overweight and obesity in four sub-Saharan African adult populations: a multi-country cross-sectional study," BMC Public Health, 16(1). doi:10.1186/s12889-016-3789-z

2. Allin, K.H. et al. (2017) "Genetic determinants of serum vitamin B12 and their relation to body mass index," European Journal of Epidemiology [Preprint]. doi:10.1007/s10654-016-0215-x.

3. Barroso, T.A. et al. (2017) "Association of Central Obesity with The Incidence of Cardiovascular Diseases and Risk Factors," International Journal of Cardiovascular Sciences [Preprint]. doi:10.5935/2359-4802.20170073.

4. Centers for Disease Control and Prevention (2013) "Physical activity and the health of young people," Retrieved February [Preprint].

5. Chikowore, T. et al. (2017) "Nutrient patterns associated with fasting glucose and glycated haemoglobin levels in a black South African population," Nutrients [Preprint]. doi:10.3390/nu9010009.

6. Ellegård, L.H. et al. (2009) "Bioelectric impedance spectroscopy underestimates fat-free mass compared to dual energy X-ray absorptiometry in incurable cancer patients," European Journal of Clinical Nutrition [Preprint]. doi:10.1038/ejcn.2008.35.

7. FAO (2018) FAOSTAT: Food Balance Sheets, FAOSTAT: Food Balance Sheets. http://faostat.fao.org/betalen/\#data/FBS (accessed 21/11/2018).

8. Finucane, M.M. et al. (2011) “National, reFinucane, M. M. et al. (2011) `National, regional, and global trends in body-mass index since 1980: Systematic analysis of health examination surveys and epidemiological studies with 960 country-years and $9 \cdot 1$ million participants', The Lancet.," The Lancet [Preprint]. doi:10.1016/S0140-6736(10)62037-5.

9. Gallagher, D. et al. (1996) "How useful is body mass index for comparison of body fatness across age, sex, and ethnic groups?," American Journal of Epidemiology [Preprint]. doi:10.1093/oxfordjournals.aje.a008733.

10. Goedecke, J.H. et al. (2009) "Insulin response in relation to insulin sensitivity: An appropriate $\beta$-cell response in black South African women," Diabetes Care, 32(5). doi:10.2337/dc08-2048.

11. Goedecke, J.H. and Olsson, T. (2020) "Pathogenesis of type 2 diabetes risk in black Africans: a South African perspective," Journal of Internal Medicine. doi:10.1111/joim.13083.

12. Guthold, R. et al. (2018) “Worldwide trends in insufficient physical activity from 2001 to 2016: a pooled analysis of 358 population-based surveys with 1.9 million participants," The Lancet Global Health [Preprint]. doi:10.1016/S2214-109X(18)30357-7.

13. Hausman, D.B. et al. (2011) "Body mass index is associated with dietary patterns and health conditions in Georgia centenarians," Journal of Aging Research [Preprint]. doi:10.4061/2011/138015.

14. Hu, F.B. (2002) "Dietary pattern analysis: A new direction in nutritional epidemiology," Current Opinion in Lipidology [Preprint]. doi:10.1097/00041433-200202000-00002.

15. Jessri, M., Lou, W.Y. and L'Abbé, M.R. (2016) “Evaluation of different methods to handle misreporting in obesity research: Evidence from the Canadian national nutrition survey," British Journal of Nutrition [Preprint]. doi:10.1017/S0007114515004237.

16. Keswell, D., Tootla, M. and Goedecke, J.H. (2016) "Associations between body fat distribution, insulin resistance and dyslipidaemia in black and white South African women," Cardiovascular Journal of Africa, 27(3). doi:10.5830/CVJA-2015-088.

17. Langenhoven, M.; Kruger, M.; Gouws, E.; Faber, M. MRC Food Composition Tables, 3rd ed.; South African Medical Research Council: Cape Town, South Africa, 1991.

18. Locke, A.E. et al. (2015) "Genetic studies of body mass index yield new insights for obesity biology," Nature [Preprint]. doi:10.1038/nature14177.

19. Makura-Kankwende, C.B.T. et al. (2021) "Nutrient patterns and body composition parameters of black South African women," Nutrients [Preprint]. doi:10.3390/nu13010006.

20. Malik, V.S. et al. (2010) "Sugar-sweetened beverages and risk of metabolic syndrome and type 2 diabetes: A meta-analysis," Diabetes Care [Preprint]. doi:10.2337/dc10-1079.

21. Mchiza, Z.J.et al. (2015) “Body image and weight control in South Africans 15 years or older: SANHANES-1," BMC Public Health [Preprint]. doi:10.1186/s12889-015-2324-y. 
22. McKeown, N.M. et al. (2010) "Whole- and refined-grain intakes are differentially associated with abdominal visceral and subcutaneous adiposity in healthy adults: The Framingham Heart Study," American Journal of Clinical Nutrition, 92(5). doi:10.3945/ajcn.2009.29106.

23. Micklesfield, L.K. et al. (2012) “Dual-energy X-ray performs as well as clinical computed tomography for the measurement of visceral fat," Obesity [Preprint]. doi:10.1038/oby.2011.367.

24. Micklesfield, L.K. et al. (2013) "Socio-cultural, environmental and behavioural determinants of obesity in black South African women," Cardiovascular Journal of Africa [Preprint]. doi:10.5830/CVJA-2013-069.

25. Di Monaco, M. et al. (2011) "Prevalence of sarcopenia and its association with osteoporosis in 313 older women following a hip fracture," Archives of Gerontology and Geriatrics [Preprint]. doi:10.1016/j.archger.2010.02.002.

26. Mtintsilana, A. et al. (2019) "Adiposity mediates the association between the dietary inflammatory index and markers of type 2 diabetes risk in middle-aged black South African women," Nutrients, 11(6). doi:10.3390/nu11061246.

27. Ng, M. et al. (2014) "Global, regional, and national prevalence of overweight and obesity in children and adults during 19802013: A systematic analysis for the Global Burden of Disease Study 2013," The Lancet [Preprint]. doi:10.1016/S01406736(14)60460-8.

28. Otang-Mbeng, W., Otunola, G.A. and Afolayan, A.J. (2017) “Lifestyle factors and co-morbidities associated with obesity and overweight in Nkonkobe Municipality of the Eastern Cape, South Africa," Journal of health, population, and nutrition [Preprint]. doi:10.1186/s41043-017-0098-9.

29. Phillips, E.A. et al. (2016) "Perceptions of diet, physical activity, and obesity-related health among black daughter-mother pairs in Soweto, South Africa: A qualitative study," BMC Public Health [Preprint]. doi:10.1186/s12889-016-3436-8.

30. Pisa, P.T. et al. (2015a) "Nutrient patterns and their association with socio-demographic, lifestyle factors and obesity risk in rural South African adolescents," Nutrients [Preprint]. doi:10.3390/nu7053464.

31. Pisa, P.T. et al. (2015b) "Nutrient patterns and their association with socio-demographic, lifestyle factors and obesity risk in rural South African adolescents," Nutrients [Preprint]. doi:10.3390/nu7053464.

32. Pisa, P.T. et al. (2018) "Different adiposity indices and their association with blood pressure and hypertension in middle-aged urban black South African men and women: Findings from the AWI-GEN South African Soweto Site," BMC Public Health, 18(1). doi:10.1186/s12889-018-5443-4.

33. Plank, L.D. (2005) “Dual-energy X-ray absorptiometry and body composition," Current Opinion in Clinical Nutrition and Metabolic Care [Preprint]. doi:10.1097/01.mco.0000165010.31826.3d.

34. Preis, S.R. et al. (2010) "Abdominal subcutaneous and visceral adipose tissue and insulin resistance in the framingham heart study," Obesity [Preprint]. doi:10.1038/oby.2010.59.

35. Puoane, T. et al. (2006) "Socio-cultural Factors Influencing Food Consumption Patterns in the Black African Population in an Urban Township in South Africa," Human Ecology Special Issue [Preprint], (14).

36. Qi, Q. et al. (2012) "Sugar-Sweetened Beverages and Genetic Risk of Obesity," New England Journal of Medicine, 367(15). doi:10.1056/nejmoa1203039.

37. Ramsay, M. et al. (2016) “H3Africa AWI-Gen Collaborative Centre: A resource to study the interplay between genomic and environmental risk factors for cardiometabolic diseases in four sub-Saharan African countries," Global Health, Epidemiology and Genomics [Preprint]. doi:10.1017/gheg.2016.17.

38. Rico-Campà, A. et al. (2019) "Association between consumption of ultra-processed foods and all cause mortality: SUN prospective cohort study," The BMJ [Preprint]. doi:10.1136/bmj.11949.

39. SADHS (2016a) South Africa Demographic and Health Survey., Statistics South Africa. doi:10.1017/CBO9781107415324.004.

40. SADHS (2016b) South Africa Demographic and Health Survey., Statistics South Africa. doi:10.1017/CBO9781107415324.004.

41. Song, Y.M., Ha, M. and Sung, J. (2007) “Body Mass Index and Mortality in Middle-Aged Korean Women,” Annals of Epidemiology [Preprint]. doi:10.1016/j.annepidem.2007.01.028.

42. Stenholm, S. et al. (2008) "Sarcopenic obesity: Definition, cause and consequences," Current Opinion in Clinical Nutrition and Metabolic Care [Preprint]. doi:10.1097/MCO.0b013e328312c37d.

43. Steyn, N.P. et al. (2006) “How well do adolescents determine portion sizes of foods and beverages?," Asia Pacific Journal of Clinical Nutrition [Preprint].

44. Steyn, N.P. et al. (2016) "Dietary intake of the urban black population of Cape Town: The cardiovascular risk in black South Africans (CRIBSA) study," Nutrients, 8(5). doi:10.3390/nu8050285.

45. Visser, M. et al. (2019) “Nutrient patterns and their relation to anemia and iron status in 5- to 12-y-old children in South Africa," Nutrition [Preprint]. doi:10.1016/j.nut.2019.01.016.

46. Vorster, H.H. et al. (2014) "Added sugar intake in South Africa: Findings from the Adult Prospective Urban and Rural Epidemiology cohort study," American Journal of Clinical Nutrition [Preprint]. doi:10.3945/ajcn.113.069005.

47. WHO (2016a) "Obesity and overweight: Fact sheet," WHO Media Centre [Preprint].

48. WHO (2016b) "Obesity and overweight: Fact sheet," WHO Media Centre [Preprint].

49. Willett, W.C. (1998) Nutritional Epidemiology, Nutritional Epidemiology. doi:10.1093/acprof:oso/9780195122978.001.0001. 
50. World Health Organization [Country Office for India] (2014) "Burden of NCDs and their risk factors in India," (Excerpted from Global Status Report on NCDs -2014 [Preprint]. doi:accessed on 14September 2017.

51. Woudberg, N.J., Lecour, S. and Goedecke, J.H. (2019) "HDL Subclass Distribution Shifts with Increasing Central Adiposity," Journal of Obesity, 2019. doi:10.1155/2019/2107178.

52. Yagan, F.C.C. et al. (2016) "The relationship between obesity and serum Vitamin B12, folic acid, vitamin D concentrations in obes adults: a retrospective study," Endocrine Abstracts [Preprint]. doi:10.1530/endoabs.41.ep183.

53. Yeom, J., Kim, J.K. and Crimmins, E.M. (2009) “Factors Associated with Body Mass Index(BMI) Among Older Adults: A Comparison Study of the U.S., Japan, and Korea.," Han'guk nonyonhak = Journal of Korea Gerontological Society [Preprint].

54. Zingoni, C. et al. (2009) "Studying a population undergoing nutrition transition: A practical case study of dietary assessment in urban South African adolescents," Ecology of Food and Nutrition, 48(3). doi:10.1080/03670240902794713. 